Bangladesh J. Sci. Ind. Res. 42(4), 367-376, 2007

\title{
Leaching of Sodium Sulphide Roasted Ilmenite Sand
}

\author{
M.K. Hasan, D.A. Begum and M.F. Islam \\ Department of Applied Chemistry and Chemical Technology \\ University of Rajshahi, Rajshahi-6205, Bangladesh
}

\begin{abstract}
The possibilities of co-leachings of Ti(IV) and Fe(III) from the roasted product of ilmenite sand with sodium sulphide at the optimum conditions by hydrochloric and sulphuric acid were investigated. The leaching was dependent on hydrochloric and sulphuric acid concentrations, temperature and leaching time. The optimum conditions for the best dissolution of Ti(IV) and $\mathrm{Fe}(\mathrm{III})$ were: temperature $100^{\circ} \mathrm{C}$, time 60 min for 1:1 ilmenite to sodium sulphide weight ratio roasted product and $10 \mathrm{~min}$ for 1:2 ilmenite to sodium sulphide weight ratio roasted product, acid concentration 4-6 $\mathrm{N}$ and agitation speed $400 \mathrm{rpm}$. About $95 \% \mathrm{Ti}(\mathrm{IV})$ and $93 \% \mathrm{Fe}(\mathrm{III})$ dissolutions were obtained from hydrochloric acid leaching and $95 \% \mathrm{Ti}(\mathrm{IV})$ and $91 \% \mathrm{Fe}(\mathrm{III})$ were obtained from sulphuric acid leaching at a solid to liquid phase ratio (S/L) of $0.10 \mathrm{~kg}$ $\mathrm{dm}^{-3}$.
\end{abstract}

Keywords: Ilmenite sand, Roasting of ilmenite sand, Sodium sulphide roasted ilmenite, Leaching of roasted product, Dissolution of titanium and iron.

\section{Introduction}

About 3.5 millon tons of heavy mineral deposits containing ilmenite have so far been discovered in the South-Eastern coastal area of Bangladesh (Mirdha and Islam, 1985). It has been reported (Biswas 1978) that the coastal sands contain more than $10 \%$ heavy minerals, which in turn contains $27 \%$ ilmenite. The ilmenite fraction of the Cox's Bazar beach sand is found to contain about $32.4 \%$ iron and $28 \%$ titanium.
Many processes have been tried for the production of titanium dioxide from ilmenite sand in many countries of the world. The beach sand exploitation center of Bangladesh Atomic Energy Commission at Cox's Bazar has succeeded in fractionating the heavy minerals (Pilot Plant Scale) from the raw beach sand of different localities (Islam et al. 1978; Awwal et al. 1976). Titanium is generally extracted as dioxide

Corresponding author, E-mail: manoranjansaha2005@yahoo.com 
from ilmenite fraction by conventional mineral acids leaching and precipitation routes. In the conventional process, a large fraction of ilmenite is being rejected un-dissolved and the co-dissolved other transition metal ions may be co-precipitated with titanium, which may seriously discolor the white pigment color of titanium dioxide. In our laboratory, a few processes have also been tested for the recovery of titanium dioxide. Titanium (IV) has been separated effectively from iron(III) present in sulphuric acid leached liquor using solvent extraction, stripping and precipitation methods (Islam et al. 1978; Islam et al. 1979; Mustafa et al. 1985). In those studies, the leach liquor was obtained by pasting the powdered ilmenite sand with concentrated sulphuric acid (sp. gr. 1.8) and heating for about $48 \mathrm{~h}$ with constant stirring. A report (Mirdha et al. 1985) was also presented in the $10^{\text {th }}$ Annual Convention of the Bangladesh Association for the Advancement of Science on the separation of titanium dioxide from other constituents in the ilmenite concentrate.

All of the techniques mentioned above for the recovery of titanium dioxide from the ilmenite sand required many steps, mostly time and reagent consuming. To overcome these problems, an effort has been provided to recover titanium dioxide from the ilmenite sand by roasting with sodium sulphide and subsequent leaching with hydrochloric and sulphuric acid as partly described in the previous report (Hasan et al. 1998). In this report, optimum time, temperature, ilmenite to sodium sulphide weight ratio and particle size of ilmenite sand for roasting were determined keeping the dissolution parameters constant. During this study, it was seen that sodium sulphide roasted ilmenite sand was leachable where time and reagent requirements were less compared with other techniques. The present report describes the effects of various parameters on titanium and iron dissolutions from the sodium sulphide roasted ilmenite mass.

\section{Materials and Methods}

Ilmenite concentrate used in all experiments was collected from Bangladesh Atomic Energy Commission Pilot Plant at Cox's Bazar. The supplied sample was ground in a ball mill and sieved to collect the $(-100+63)$ micron particle sizes using a sieve shaker. A. R. grade hydrochloric and sulphuric acids were obtained from the E. Marck, and sodium sulphide from BDH Pvt. Ltd.

\section{Procedures}

\section{Analysis of roasted mass}

The selected classified sand was roasted with sodium sulphide in an aluminum oxide crucible for a predetermined optimum time (100 min) and temperature $\left(800^{\circ} \mathrm{C}\right)$ as reported earlier (Hasan et al. 1998). The roasted products for different ilmenite to sodium sulphide weight ratios were analyzed colorimetrically (Vogel 1961) after fusing the roasted mass $(0.5 \mathrm{~g})$ with 20 times of its 
weight of $\mathrm{KHSO}_{4}$ in a platinum crucible for $1 \mathrm{~h}$. The fused mass was dissolved in $15 \%$ sulphuric acid and made up to the mark in a $500 \mathrm{ml}$ volumetric flask with $15 \%$ sulphuric acid. The actual percentages in the roasted mass were calculated from this colorimetric analysis. Data are given in Table I.
$\mathrm{TiO}_{2}$ ). It is also found that the thermally stable $\mathrm{Fe}_{2} \mathrm{TiO}_{5}$ phase transforms to the metastable $\mathrm{Fe}_{2} \mathrm{Ti}_{3} \mathrm{O}_{9}$ phase during milling in oxygen. The different behaviors of the oxidation of ilmenite between thermal annealing and mechanical milling are due to different structural stabilities of oxides and

Table I. Data for the actual percentage of titanium dioxide and $\mathrm{Fe}_{2} \mathrm{O}_{3}$ in the roasted product of different ratios of ilmenite to sodium sulphide used in roasting. Original ilmenite composition: $\mathrm{Fe}-32.4 \%$ corresponding to $45.36 \% \mathrm{Fe}_{2} \mathrm{O}_{3}$ and $\mathrm{Ti}-27.8 \%$ corresponding to $46.4 \%$ $\mathrm{TiO}_{2}$.

\begin{tabular}{c|c|c|c}
\hline $\begin{array}{c}\text { Weight ratio of } \\
\mathrm{TiFeO}_{3}: \mathrm{Na}_{2} \mathrm{~S}\end{array}$ & $\begin{array}{c}\text { Actual \% of } \mathrm{TiO}_{2} \\
\text { in the sample }\end{array}$ & $\begin{array}{c}\text { Actual \% of } \mathrm{Fe}_{2} \mathrm{O}_{3} \\
\text { in the sample }\end{array}$ & Percentage of $\mathrm{Cr}_{2} \mathrm{O}_{3}$ \\
\hline $1: 1$ & 24.0 & 32.2 & \\
$1: 2$ & 19.5 & 26.7 & $\begin{array}{c}\text { 0.058 } \\
1: 3\end{array}$ \\
$1: 4$ & 16.3 & 21.0 & $\begin{array}{c}\text { Hasan et al. 1998) } \\
\text { (from previous report }\end{array}$ \\
$1: 5$ & 14.0 & 16.4 & \\
\hline
\end{tabular}

The variations could arise at different oxidizing conditions where conditions can vary due to temperature variations etc. Oxidation reactions of ilmenite $\left(\mathrm{FeTiO}_{3}\right)$ have been investigated (Chen Y, 1998) during thermal annealing and ball milling processes using X-ray diffraction and thermal analyses. Thermal oxidation reactions consist of a low-temperature $\left(<1000^{\circ} \mathrm{C}\right)$ reaction with the formation of intermediate phases $\left(\mathrm{Fe}_{2} \mathrm{Ti}_{3} \mathrm{O}_{9}\right.$ and $\left.\mathrm{Fe}_{2} \mathrm{O}_{3}\right)$ and high-temperature $\left(>1000^{\circ} \mathrm{C}\right)$ reactions with the formation of final thermally stable phases $\left(\mathrm{Fe}_{2} \mathrm{TiO}_{5}\right.$ and different reaction mechanisms. However, the present work is only for preparative study.

\section{Leaching of roasted mass}

The dissolution of $5 \mathrm{~g}$ roasted product was carried out with different concentrations of acids (hydrochloric and sulphuric) at a solid to liquid phase ratio (S/L) of $0.10 \mathrm{~kg} \mathrm{dm}^{-3}$ at different temperatures for different times. A quick-fit condenser equipped with a flat-bottomed conical flask was used for leaching. A magnetic hot plate stirrer was used for heating and mixing the contents of the flask. At 
intervals, duplicate aliquots $(0.5 \mathrm{ml})$ of the solution were removed, filtered, diluted and analyzed colorimetrically; one for titanium (IV) and other for iron(III). After leaching, all the leached residues were filtered off, dried and fused with potassium bisulphate to analyze the percentages of titanium dioxide, ferric oxide and chromic oxide retained in the unreacted roasted mass. The compositions of the residues are given in Table II. This composition has been calculated with respect to the weight of residues. Table II shows the weight percentages of metals in leached residue with increasing ilmenite to sodium sulphide weight ratio for leaching with both the acids.

It is observed that the percentage of residue formed decreases with increasing ilmenite to sodium sulphide ratio used in roasting. However, minimum percentage of residue is obtained with 1:4 ilmenite to sodium sulphide weight ratio roasted mass. From the data on weight percentage of metals left in the residue, it is evident that 2 - $4 \mathrm{~N}$ of acids show preferential leaching for iron from 1:2 - 1:5 ratios of roasted masses. Most of the chromium present in the roasted mass goes into solution.

\section{Results and Discussion}

The effect of time on leaching has been determined by treating the $1: 2$ roasted mass with $4 \mathrm{~N} \mathrm{HCl}$ and $\mathrm{H}_{2} \mathrm{SO}_{4}$ at constant S/L ratio of $0.10 \mathrm{~kg} \mathrm{dm}^{-3}$ at their boiling points and shown in Fig. 1. From the effect of time on leaching data, it is observed that the maximum dissolution percentage of titanium is obtained at about $10 \mathrm{~min}$ and then decreased with increasing leaching time while the dissolution percentage of iron is increased with increasing leaching time and the maximum dissolution weight percentage is obtained at $60 \mathrm{~min}$.

For the determination of effect of acid concentration, the leaching characteristics of roasted product in both acids show that considerable amounts of titanium and iron are dissolved in $2 \mathrm{~N}$ acid solutions at their boiling points. The weight percentages of titanium and iron dissolved at various leaching intervals have been calculated from the percentage of titanium and iron existing in the roasted mass. The maximum percentages of both metals dissolved as functions of acid concentrations are represented graphically in Figs. 2-4 for 1:1, 1:2 and 1:5 ilmenite to sodium sulphide weight ratio, respectively.

From Figs. 2 and 3, it is seen that the maximum dissolution weight percentages of both metals are increased with increasing acid concentration, particularly up to $6 \mathrm{~N}$ for $1: 1$ and 1:2 roasted masses and with further increase in the concentration of acid, the dissolutions increased only slightly. The maximum weight percentages of titanium and iron dissolved at the optimum concentration (6 N) of acid are: Ti: $76.27 \%$; Fe: $84.74 \%$ in $\mathrm{HCl}$ and $\mathrm{Ti}: 35.99 \%$; Fe: $75.60 \%$ in $\mathrm{H}_{2} \mathrm{SO}_{4}$ for $1: 1$ roasted mass. The maximum 


\begin{tabular}{|c|c|c|c|c|c|c|c|}
\hline \multicolumn{8}{|r|}{ 녕 } \\
\hline \multirow{5}{*}{\multicolumn{2}{|c|}{ 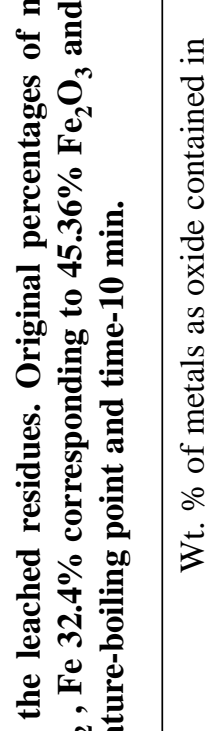 }} & & $\overbrace{\substack{n \\
\overbrace{}^{n}}}^{m}$ & 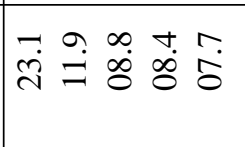 & 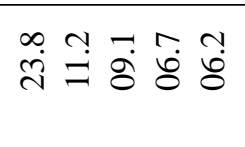 & 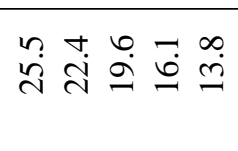 & 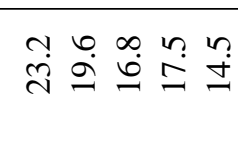 \\
\hline & & & $\stackrel{O}{E}^{N}$ & 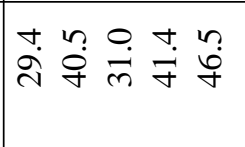 & 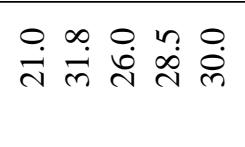 & 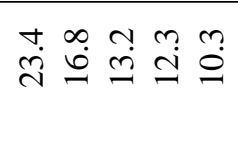 & 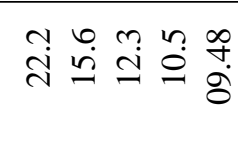 \\
\hline & & \multirow{3}{*}{ 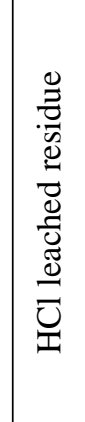 } & 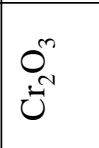 & 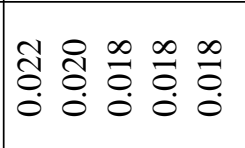 & 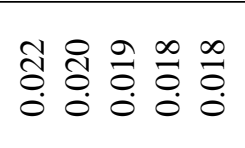 & 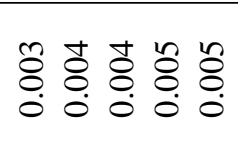 & 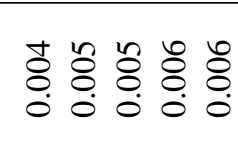 \\
\hline & & & 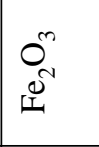 & 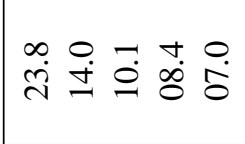 & 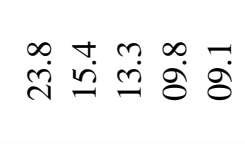 & 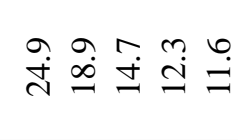 & 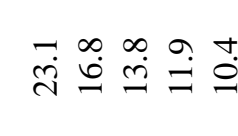 \\
\hline & & & $\stackrel{O}{E}^{N}$ & 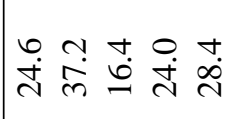 & 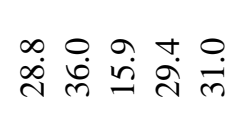 & 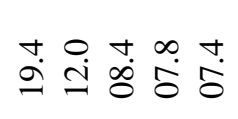 & 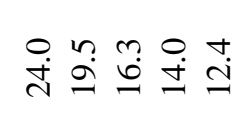 \\
\hline \multirow{5}{*}{ 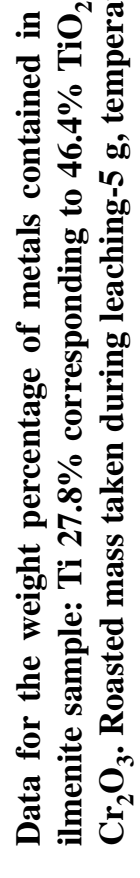 } & \multirow{4}{*}{ 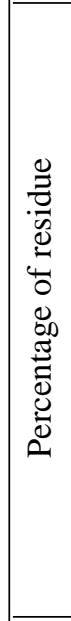 } & \multirow{2}{*}{ 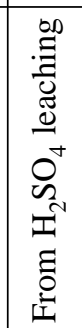 } & 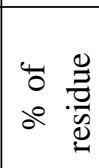 & 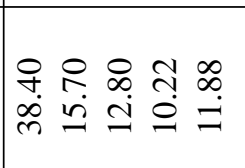 & 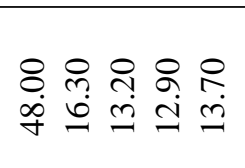 & 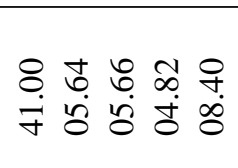 & 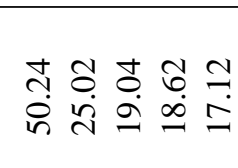 \\
\hline & & & 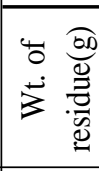 & 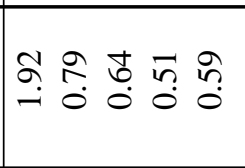 & 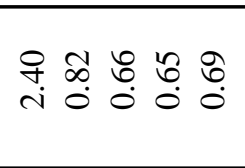 & 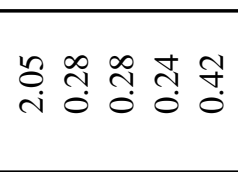 & 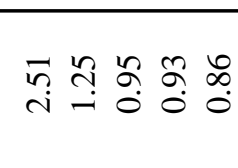 \\
\hline & & \multirow[b]{2}{*}{$\bar{E}$} & 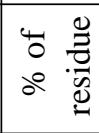 & 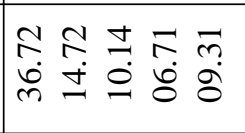 & 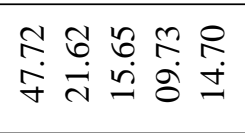 & 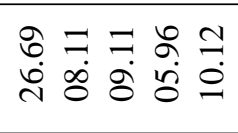 & 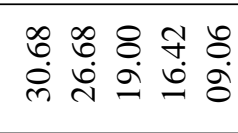 \\
\hline & & & 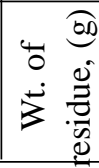 & 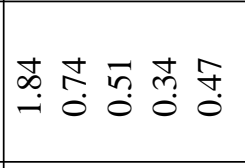 & 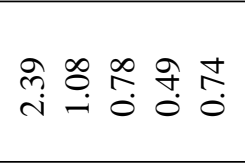 & 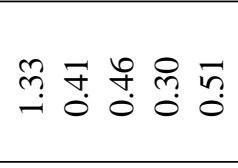 & 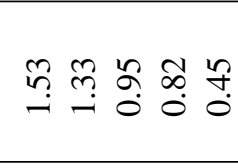 \\
\hline & \multicolumn{3}{|c|}{ 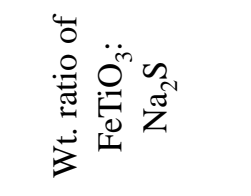 } & 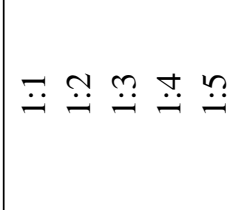 & 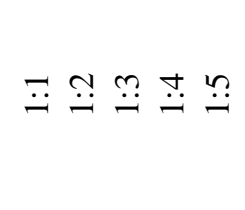 & 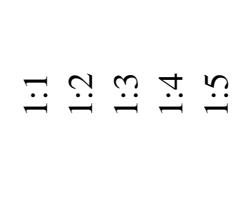 & 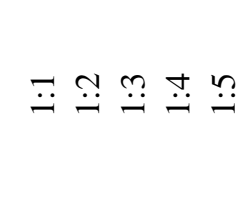 \\
\hline 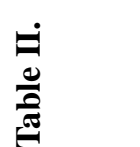 & \multicolumn{3}{|c|}{ 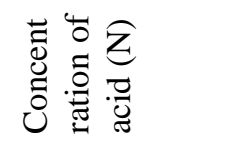 } & $N$ & $\checkmark$ & 6 & $\infty$ \\
\hline
\end{tabular}




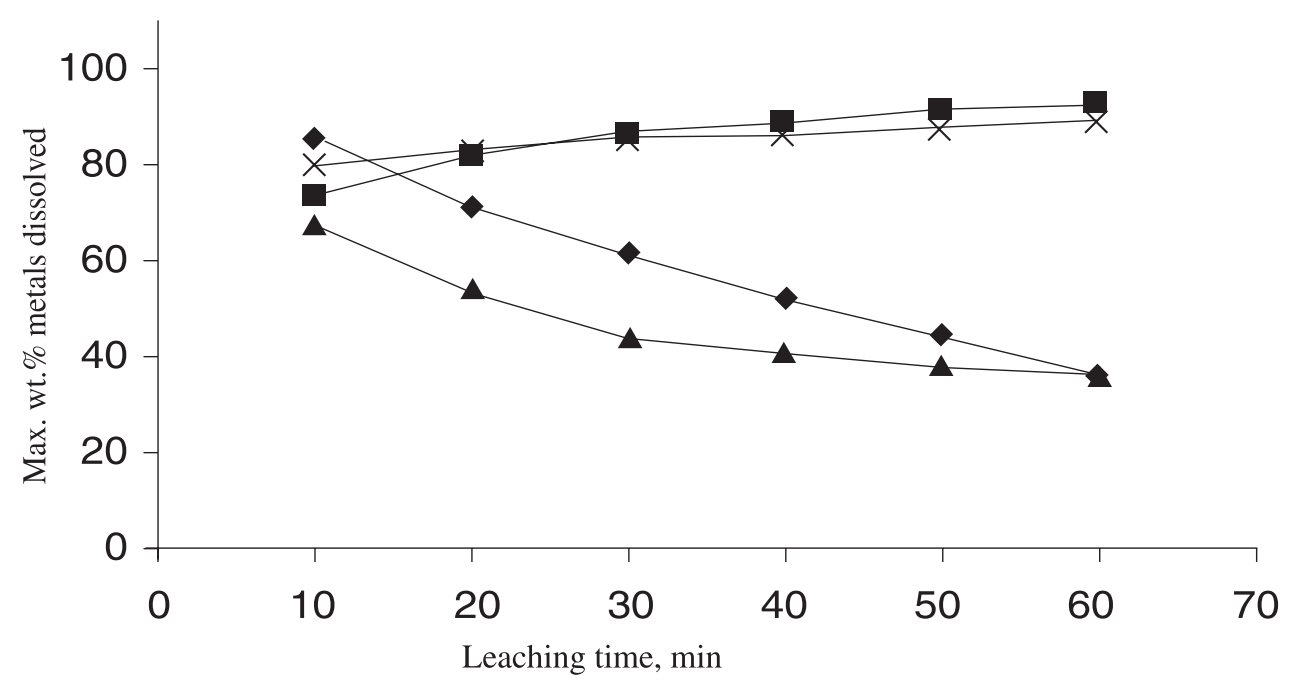

Fig. 1. Effect of time on the leaching characteristics of $1: 2 \mathrm{TiFeO}_{3}: \mathrm{Na}_{2} \mathrm{~S}$ weight ratio roasted product. Roasting condition: Particle size of ilmenite $=(-100+63)$ micron, temperature $=$ $800^{\circ} \mathrm{C}$ time $=100 \mathrm{~min}$. Leaching condition: Acid concentration $=4 \mathrm{~N}$ temperature $=$ boiling point, time $=60 \mathrm{~min}, \mathrm{~S} / \mathrm{L}$ ratio $=0.10 \mathrm{~kg} \mathrm{dm}^{-3}$, agitation speed $=400 \mathrm{rpm} .(\diamond) \mathrm{Ti},($ ) Fe in $\mathrm{HCl} ;(\Delta) \mathrm{Ti},(\times) \mathrm{Fe}$ in $\mathrm{H}_{2} \mathrm{SO}_{4}$.

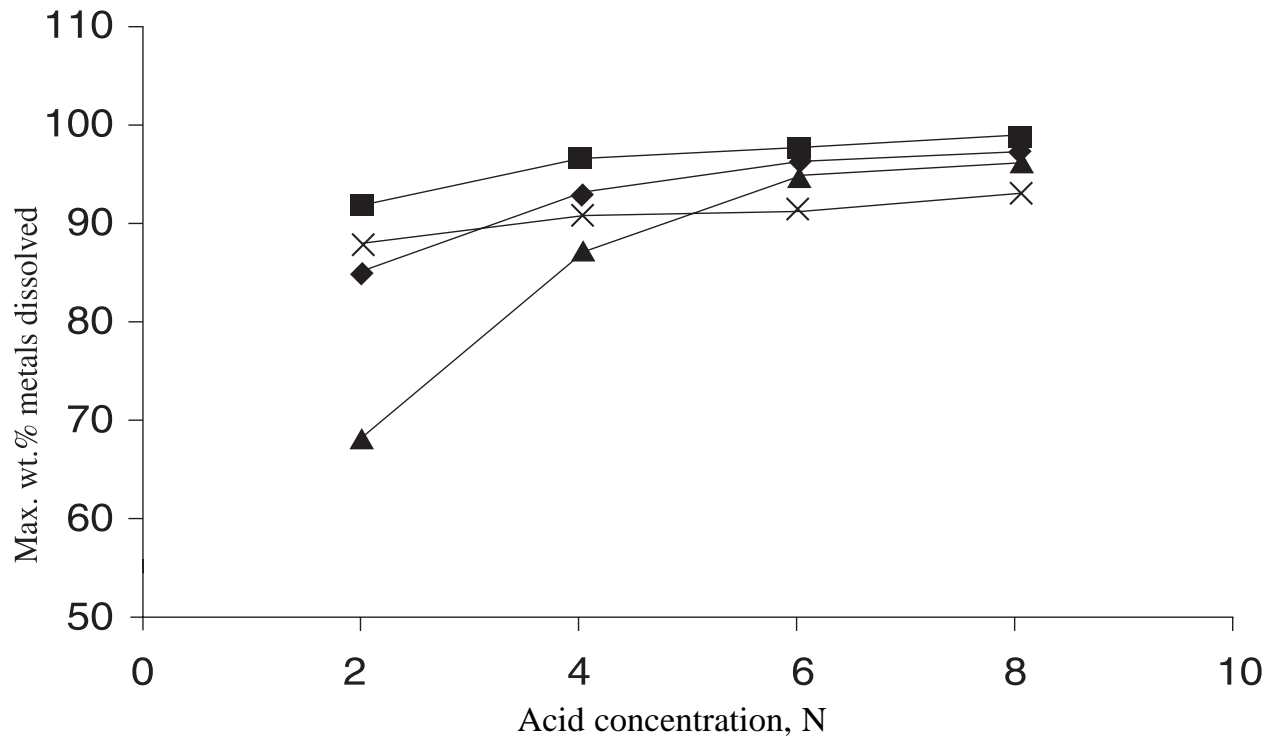

Fig. 2. Effect of acid concentration on the leaching characteristics of $1: 1 \mathrm{TiFeO}_{3}: \mathrm{Na}_{2} \mathrm{~S}$ weight ratio roasted product. Roasting and leaching conditions except the variation of acid concentration and the symbols used are as in Fig. 1 


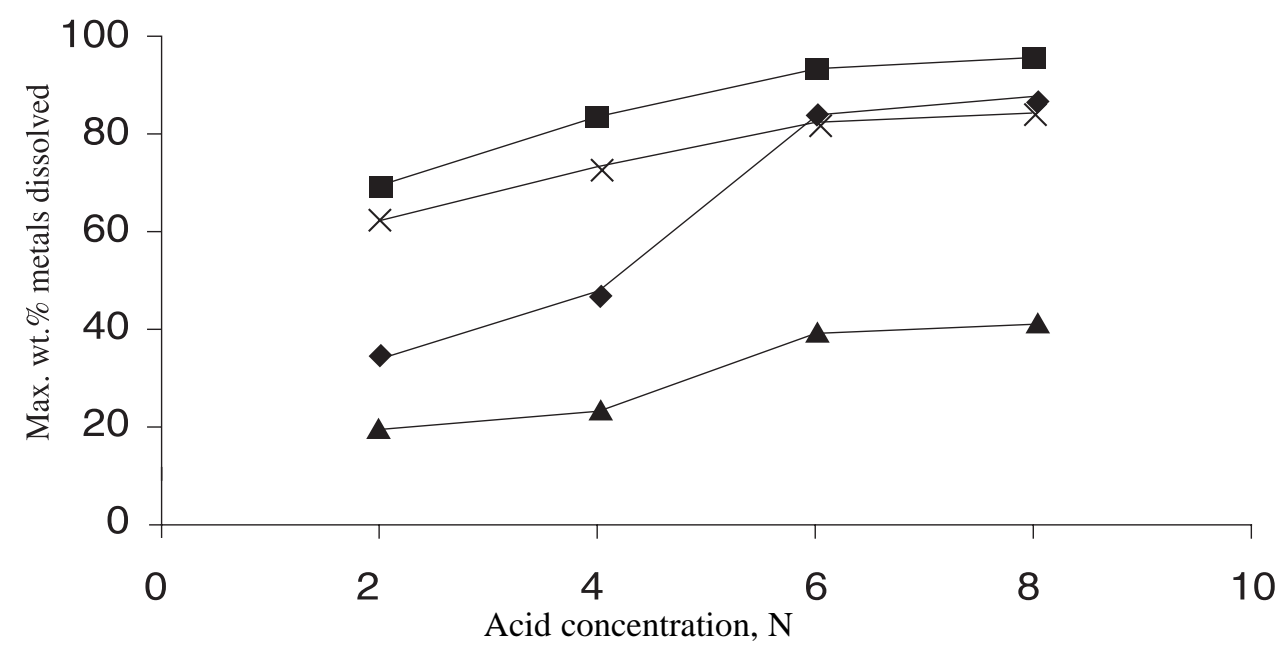

Fig. 3. Effect of acid concentration on the leaching characteristics of $1: 2 \mathrm{TiFeO}_{3}: \mathrm{Na}_{2} \mathrm{~S}$ weight ratio roasted product. Roasting and leaching conditions and the symbols used are as in Fig. 1.

dissolution weight percentages are increased to Ti: $96.00 \%$, Fe: $97.50 \%$ in $\mathrm{HCl}$ and Ti: $94.68 \%$, Fe: $91.50 \%$ in $\mathrm{H}_{2} \mathrm{SO}_{4}$ for $1: 2$ roasted mass.

The dissolutions of 1:3, 1:4 and 1:5 roasted products show similar trends. Only the maximum dissolution weight percentages of titanium and iron for 1:5 ratio is represented graphically in Fig. 4. It indicates that the maximum dissolution weight percentages of titanium dissolved in both acids is gradually increased with increasing acid concentration. On the other hand, the maximum dissolution weight percentages of iron dissolved in $\mathrm{HCl}$ is gradually decreased with increasing acid concentration. However, in the $\mathrm{H}_{2} \mathrm{SO}_{4}$ leaching, it is first increased up to $4 \mathrm{~N}$ and then decreased with increasing acid concentra tion. It is therefore, concluded that $4 \mathrm{~N}$ of both acids is suitable for the leaching of $1: 3$, 1:4 and 1:5 roasted products to dissolve maximum weight percentages of both metals. These percentages are: $\mathrm{TiO}_{2}$ : $~ 99 \%$ and Fe: $95 \%$.

To determine the effect of temperature on leaching, $5 \mathrm{~g}$ of 1:4 roasted mass has been leached with $4 \mathrm{~N}$ hydrochloric and sulphuric acids at various temperatures keeping constant $\mathrm{S} / \mathrm{L}$ of $0.10 \mathrm{~kg} \mathrm{dm}^{-3}$. The maximum weight percentages of titanium dioxide and iron dissolved in both acids have been calculated and shown as a function of leaching temperature in Fig. 5.

It is observed that the maximum dissolution weight percentages of both metals are 


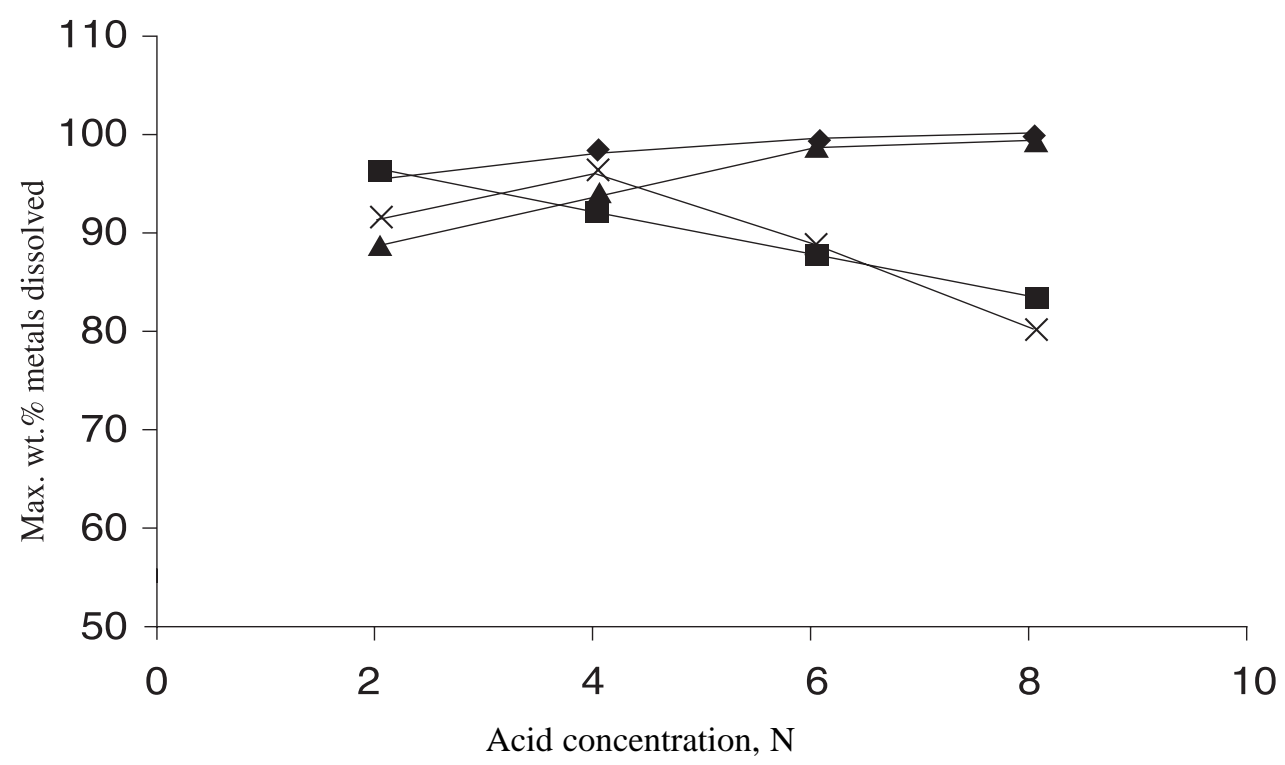

Fig. 4. Effect of acid concentration on the leaching characteristics of $1: 5 \mathrm{TiFeO}_{3}: \mathrm{Na}_{2} \mathrm{~S}$ weight ratio roasted product. Roasting and leaching conditions and the symbols used are as in Fig. 1.

increased with increasing leaching temperature. The variation is very sharp between 60 to $90^{\circ} \mathrm{C}$. The maximum weight percentage dissolutions of both metals at optimum leaching temperature are: $\mathrm{Ti} 98.8 \%$, Fe $81.9 \%$ in $\mathrm{HCl}$ and Ti $95.93 \%$, Fe $87.5 \%$ in $\mathrm{H}_{2} \mathrm{SO}_{4}$, respectively. A similar result was also reported (Tolley 1981) for leaching of $\mathrm{H} / \mathrm{H}-\mathrm{CO}$ reduced $\left(600-1000^{\circ} \mathrm{C}\right)$ ilmenite by $\mathrm{HCl}$. The leaching of ilmenite in $\mathrm{HCl}$ has also been investigated (Sinha 1984) and reported that the reactivity of ilmenite for leaching with 20 weight $\% \mathrm{HCl}$ at $108-110^{\circ}$ $\mathrm{C}$ is increased by prior oxidation at $950^{\circ} \mathrm{C}$ and reduction at $850^{\circ} \mathrm{C}$ of ilmenite.

From the leaching of different ilmenite to sodium sulphide roasted masses, it is observed that the maximum dissolutions of titanium and iron are obtained from 1:1 ratio roasted product for 60 min leaching time. In the leaching of 1:2, 1:3, 1:4 and 1:5 ratios roasted products, it is observed that maximum dissolution of titanium is obtained at $10 \mathrm{~min}$ and maximum iron dissolution is obtained at $60 \mathrm{~min}$.

Although, it has been reported (Belyakova et al. 1963) that the ilmenite (without roasting) may be leached by boiling with $18 \mathrm{~N}$ sulphuric acid for two days and is partially leachable with $20 \% \mathrm{HCl}$ under high pressure and temperature but this investigation shows that much weaker acid solutions are effective after sodium sulphide roasting. In 


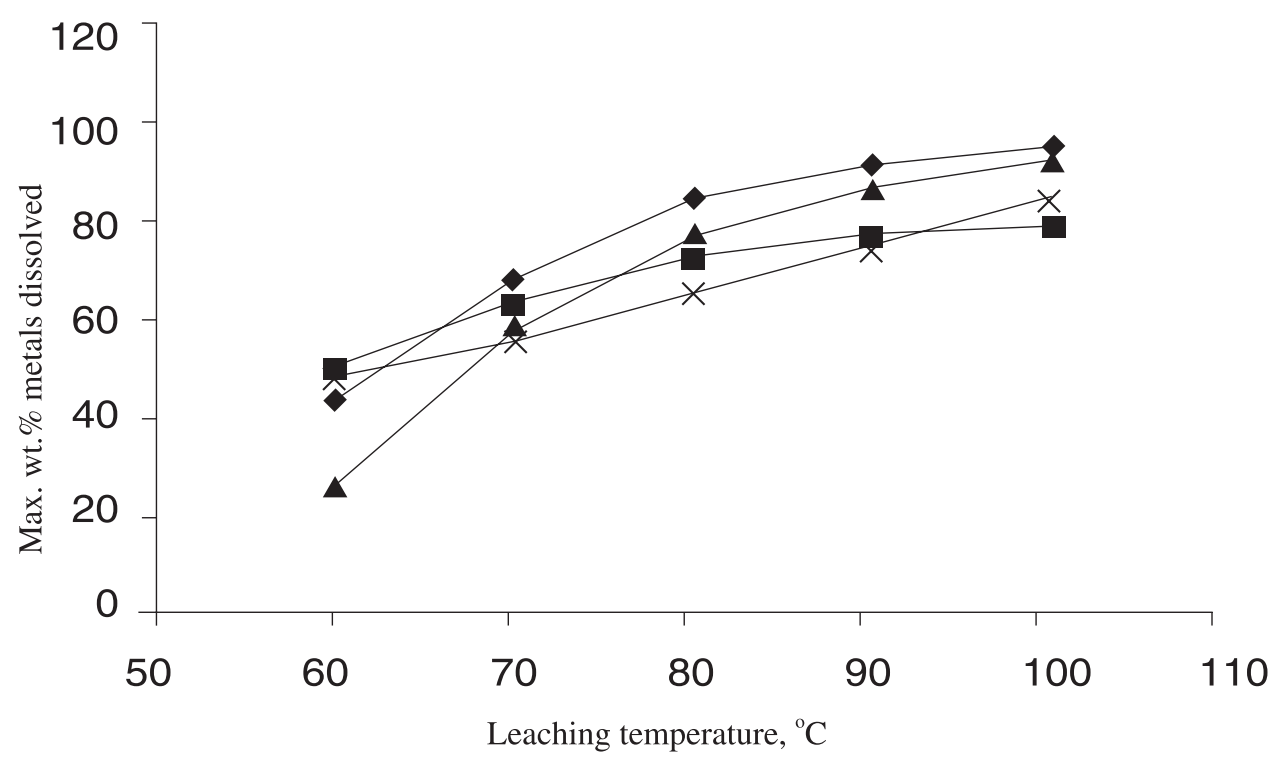

Fig. 5. Effect of temperature on the leaching characteristics of $1: 4 \mathrm{TiFeO}_{3}: \mathrm{Na}_{2} \mathrm{~S}$ weight ratio oasted product. Roasting and leaching conditions except in leaching at variable temperature and the symbols used.are as in Fig. 1

contrast, about $81 \%$ titanium and $26 \%$ of iron are reported to be dissolved (Biswas et al. 1987) with $6.4 \mathrm{~N} \mathrm{HF}$ acid in $5 \mathrm{~h}$. However, the HF acid is highly corrosive for most reaction vessels and the leaching time is longer as found earlier for concentrated HF acid leaching (Hansen and Traut, 1989). The use of concentrated acid solutions is often accompanied by high loss of acid.

\section{Conclusions}

This investigation shows the effectiveness of sodium sulphide roasting of ilmenite for leaching with less concentrated acids ( $\mathrm{HCl}$ and $\mathrm{H}_{2} \mathrm{SO}_{4}$ ) for obtaining titanium(IV) leach liquors. The leaching time is also much shorter compared to leaching of non-treated ilmenite with hydrochloric, sulphuric or hydrofluoric acid. A lower leaching temperature can be used. The leaching was performed under atmospheric pressure. Leaching of iron(III) and Ti(IV) is not only affected by time, temperature, acid concentration and stirring speed but also dependent on the ilmenite: $\mathrm{Na}_{2} \mathrm{~S}$ weight ratio used in roasting. This study shows only the feasibility of using a cheap chemical like sodium sulphide to decompose a very inactive mineral ilmenite for subsequent leaching with common acids like $\mathrm{HCl}$ and $\mathrm{H}_{2} \mathrm{SO}_{4}$. The identification of the product formed on by $\mathrm{Na}_{2} \mathrm{~S}$ roasting can be investigated by further sophisticated work, e.g., XRD and related analyses, which have however yet to be done. 


\section{Acknowledgement}

The authors are very much grateful to Bangladesh Atomic Energy Commission Pilot Plant at Cox's Bazar for supplying the ilmenite sand in our Laboratory.

\section{References}

Awwal, M.A. Tarafder, S.A. and Huq, A.M. (1976) Nucl. Sci. Appl. 9(B) 43.

Belyakova, E.P. Dvernyakova, A.A. (1963) Ukr. Khim. Zh., 29 : 220.

Biswas, M.A.B. (1978) Nucl. Sci. Appl., 11 : 43 and 75.

Biswas, M.A.B. (1987) A letter of beach sand exploitation center of Bangladesh Atomic Energy Commission at Kalatali, Cox's Bazar to Islam, M. F. 11(2)/87.

Chen, Y. (1998) Journal of Alloys and Compounds, Elsevier Science, V. 266, Issues 1-2, 150-154.

Hansen, D.A. and Traut, D.E. (1989) J. Metal. (5) 34-36; Chem. Abs. 111 :118516m.

Hasan, K. Afroz, D. and Islam, F. (1998) Sodium sulphide roasting of ilmenite for acid leaching - Effect of roasting parameters. Bangladesh J. Sci. Ind. Res. 33(3) : 444 448.
Islam, F. Ali, M. and Akhter, S. (1978) Bangladesh J. Sci. Ind. Res., 13 : 220.

Islam, F. Biswas, R.K. and Mustafa, C.M. (1985) Hydrometallurgy 13 : 365.

Islam, F. Rahman, H. Ali, M. (1979) J. Inorg. Nucl. Chem., 41 : 217.

Mirdha, S. and Islam, M.S. (1985) Report presented at the $10^{\text {th }}$ Annual Convention of Bangladesh Association for the Advancement of Science, Dhaka.

Sinha, H.N. (1984) Symp. Ser. Australias Inst. Min. Metal. 36, Chem. Abs. 102 :135596u.

Tolley, W.K. (1981) Ger. Offen, 2, 944, 239 (cl C01G28/04); Chem. Abs. 95 : 99980r.

Vogel, A.I. (1961) A text book of quantitative inorganic analysis including elementary instrumental analysis (3rd Ed.) (Longmans, Green and Co. Ltd. 48 Grosvenor Street, London, W. 1) 1961, pp-786 and 788.

Received : October, 27, 2005;

Accepted : September, 9, 2007 